OPEN ACCESS

Edited by:

Lizza E. L. Hendriks,

Maastricht University Medical Centre,

Netherlands

Reviewed by:

Rachel E. Sanborn,

Providence Portland Medical Center,

United States

Qing Yuan,

Southwest Medical University, China

Monique Hochstenbag,

Maastricht University Medical Centre,

Netherlands

${ }^{*}$ Correspondence:

Bin Xiong

xionbin321@163.com

Zhangyong Song

szy83529@163.com

Specialty section: This article was submitted to

Thoracic Oncology,

a section of the journal

Frontiers in Oncology

Received: 27 June 2020 Accepted: 30 November 2020

Published: 18 January 2021

Citation:

Ran Z, Liu J, Wang F, Xin C, Xiong B and Song $Z$ (2021) Pulmonary

Micro-Ecological Changes and

Potential Microbial Markers in Lung

Cancer Patients.

Front. Oncol. 10:576855.

doi: 10.3389/fonc.2020.576855

\section{Pulmonary Micro-Ecological Changes and Potential Microbial Markers in Lung Cancer Patients}

\author{
Zhuonan Ran ${ }^{1}$, Jiexing Liu ${ }^{1}$, Fen Wang ${ }^{2}$, Caiyan Xin ${ }^{2}$, Bin Xiong ${ }^{1 *}$ \\ and Zhangyong Song ${ }^{2,3 *}$ \\ 1 The Second Department of Pulmonary and Critical Care Medicine, The Affiliated Hospital of Southwest Medical University, \\ Luzhou, China, ${ }^{2}$ School of Basic Medical Sciences, Southwest Medical University, Luzhou, China, ${ }^{3}$ Molecular Biotechnology \\ Platform, Public Center of Experimental Technology, Southwest Medical University, Luzhou, China
}

The relationship between the microbiome and disease has been investigated for many years. As a highly malignant tumor, biomarkers for lung cancer are diverse. However, precision of these biomarkers has not yet been achieved. It has been confirmed that lung microecology changes in lung cancer patients compared with healthy individuals. Furthermore, the abundance of some bacterial species shows obvious changes, suggesting their potential use as a microbial marker for the detection of lung cancer. In addition, recent studies have confirmed that inflammation, immune response, virulence factors, and metabolism may be potential mechanisms linking the microbiome with carcinogenesis. In this review, microbiome studies of lung cancer, potential mechanisms, potential microbial markers, and the influence of the microbiome on the diagnosis and treatment of lung cancer are summarized, providing theoretical strategies for the diagnosis and treatment of lung cancer.

Keywords: lung neoplasms, genomics, biodiversity, biomarker, high-throughput sequencing

\section{HIGHLIGHTS}

- The relationship between the pulmonary microbiome and lung cancer has been recognized.

- The potential mechanisms linking the microbiome with carcinogenesis are summarized.

- Potential microbial markers of some bacterial species for lung cancer are highlighted.

\section{INTRODUCTION}

In recent years, the relationship between the microbiome and disease has attracted wide attention. Many investigations have revealed that pathogen infection can lead to various diseases (1-3). For example, the correlation between Helicobacter pylori and gastrointestinal diseases has been confirmed (4). With the development of sequencing technology, the relationship between the pulmonary microbiome and health is being gradually recognized $(3,5,6)$. Compared with healthy individuals, lung cancer patients exhibit changes in the abundance of different microbial species in 
the lung microbiome, which can cause an imbalance in the immune response $(7,8)$. Furthermore, inflammation caused by an imbalanced immune response can promote the development of various cancers, including ovarian cancer (9), colon cancer (10), and stomach cancer (11). It has been reported that approximately $15 \%$ of cancers are associated with chronic inflammation $(12,13)$. Chronic inflammation of the pulmonary system has also been reported to increase the risk of lung cancer $(14,15)$. However, until now, it has been challenging to reveal the mechanisms underlying alterations of the lung microbiome and to confirm their contributions to the development of lung cancer. In this review, the changes in the pulmonary microbiome in lung cancer are summarized. The relationship between the imbalanced immune response, caused by changes in pulmonary microecology, and lung cancer is also explored. In addition, potential microbial markers for lung cancer are highlighted, which will provide a new viewpoint for early screening and diagnosis of lung cancer.

\section{LUNG CANCER}

As a highly malignant tumor, the incidence and mortality of lung cancer is high $(16,17)$. The 5 -year survival rate of patients with nonsmall cell lung cancer (NSCLC) is $21 \%$, while the 5 -year survival rate of patients with small cell lung cancer (SCLC) is only 7\% (18). The predisposing factors and pathogenesis of lung cancer are complex and have not been completely defined. A recent study found that the presence of inflammation-inducing bacterial endotoxin lipopolysaccharide (LPS) in smoke can cause genetic changes. There were significant changes in the expression levels of 1,064 genes following LPS exposure in mice. Of these genes, 859 genes were related to tumorigenesis and metastasis. These results suggested that inflammation-inducing factors in cigarette smoke can cause early epigenetic changes in the lung, which, together with other factors (e.g., environmental, genetic), can cause lung cancer (19). A retrospective meta-analysis showed that previous pulmonary diseases, such as pulmonary tuberculosis, chronic obstructive pulmonary disease (COPD), emphysema, chronic bronchitis, and pneumonia, increase the risk of lung cancer (14). The release of tumor necrosis factor (TNF) caused by Mycobacterium tuberculosis infection leads to pulmonary inflammation, and pulmonary fibrosis induced by $M$. tuberculosis results in synthesis of extracellular matrix (ECM) components. Thus, pulmonary inflammation and the ECM may be involved in the development of lung cancer (20). Epidemiological evidence suggests that tissue damage caused by inflammation can initiate or promote the development of lung cancer (21). These studies suggest that chronic inflammation is also a predisposing factor for lung cancer. Moreover, microorganisms have also been shown to influence the curative effect of lung cancer treatments. Programmed cell death-1 (PD-1)/programmed cell death 1 ligand $1(\mathrm{PD}-\mathrm{L} 1)$ inhibitor antibodies can effectively improve the 5 -year survival rate and overall survival of advanced NSCLC $(22,23)$. Further investigations showed that the efficacy of anti-PD-1 cancer treatment would be affected by intestinal microflora. In a germ-free mouse model, fecal microbiota transplantation ameliorated the antitumor effects of
PD-1 blockade (24-27). Fecal bacteria transplantation can also enhance the curative effect of chemotherapy drugs $(28,29)$. In summary, current data illustrates that the microbiome is associated with the development of lung cancer.

\section{MICROORGANISMS, INFLAMMATION, AND CANCER}

\section{Microbiome}

The microbial community of the human respiratory tract can be roughly divided into oral/nasal, upper respiratory, and pulmonary microbiomes. Due to direct communication with the outside, the oral and nasal cavity often changes with the environment, which in turn affects the microbial community of the upper respiratory tract. With the development of the endoscopic technique and gene sequencing technology, researchers have confirmed that healthy lungs are teeming with microbes, and lung microbes have been divided into the lung microbiome and lung mycobiome (30). Oral "microaspiration" has been shown to play an important role in the colonization of lung microorganisms. Comparison between oral specimens, protected specimen brushing (PSB), and bronchoalveolar lavage (BAL) specimens found that oral microflora and pulmonary microflora are similar, which confirmed that the colonized microflora in the lungs of healthy individuals migrated from the microaspiration of oral microflora (31-33). Sputum, BAL, and lung biopsy are commonly used to obtain specimens of lung microorganisms. Pollution of oral and upper respiratory tract can be avoided in BAL samples obtained by bronchoscopy and lung biopsy (31). However, these procedures are invasive, not readily available, and cause patient discomfort, and thus, their use has been limited in the study of the pulmonary microbiome. Although sputum may be contaminated by microflora from the oral and upper respiratory tract, the characteristics of the microbial community detected in sputum were closely related to tobacco smoking, severity of disease, pulmonary infection, and antibiotics use (34-36). Sputum is commonly used in many investigations because it is easily obtained, non-invasive, and reproducible $(37,38)$. The isolation and identification of lung microorganisms can be conducted by culture or non-culture methods. However, approximately $95 \%$ of lung microorganisms could not be detected by culture methods (39).

Investigations of the lung microbiome are currently unfolding. Analysis of sputum, BAL, oral, and nasopharyngeal specimens from healthy individuals found that there was no significant difference in different parts of the respiratory tract. Firmicutes and Bacteroides were found to be dominant in the lung microbiome of healthy individuals $(40,41)$. In terms of fungi, sequencing of oral washes (OWs), induced sputa (IS), and BAL from healthy individuals found that the mycobiomes of OWs, IS, and BAL had both common organisms as well as distinct members. Overlapping of BAL and OWs communities in healthy hosts suggested that lung microbes might originate from the mouth. Candida was the dominant species in OWs and IS (42). These studies show that even in the pulmonary systems of healthy individuals, the microbial community structure and composition is unique. 
The microbiome not only acts on the colonized organs locally, but also on the whole body through inflammation, immunity, metabolism, and other mechanisms. For example, the increase in urea concentration in patients with chronic kidney disease will cause a change in intestinal flora and promote the production of intestinal endotoxin, which will adversely affect kidney function (43). Intestinal flora is involved in the pathogenesis of non-alcoholic fatty liver disease by affecting intestinal barrier function, choline metabolism, bile acid synthesis, and production of short-chain fatty acids and amino acids (44). The gut microbiota can increase the concentration of circulating short-chain fatty acids (SCFAs) by metabolizing the fiber. High circulating levels of SCFAs can protect the lung from allergic inflammation by inhibiting histone deacetylase and inducing myelopoiesis $(45,46)$. This indicates that the microbiome not only acts on the colonized organs locally, but also acts on the whole body through inflammation, immunity, metabolism, and other mechanisms.

\section{Microbiome and Cancer}

A link between microbial infections and the development of cancer has been demonstrated. COPD is an important independent risk factor for lung cancer $(47,48)$. Chronic inflammation is a key characteristic of COPD (49). In most stable COPD patients also exists potentially pathogenic microorganism colonization $(50,51)$. Inflammation, oxidative stress, immunity, and DNA damage may increase the risk of lung cancer in COPD patients (52). This suggests that chronic respiratory infection may increase the body's susceptibility to carcinogens and results in a higher risk of lung cancer. A meta-analysis indicated that infection with $M$. tuberculosis may increase the risk of lung cancer (14). H. pylori infection may also promote the occurrence and development of lung cancer (53), suggesting that pathogenic microbial infections can increase the risk of lung cancer. Microorganisms can promote the occurrence of lung cancer through inflammation, immune responses, virulence factors, and metabolism; inflammatory factors, such as interleukin (IL), tumor necrosis factor (TNF)- $\alpha$, and cyclooxygenase (COX)-2, are closely related to carcinogenesis (12). IL-4 can promote tumor growth by inducing cathepsin protease activity in tumor-associated macrophages (54). In addition, NSCLC cells underwent a gradually progressing epithelial-to-mesenchymal (EMT) phenotype following exposure to IL-1 $\beta$, an abundant proinflammatory cytokine in at-risk for lung cancer pulmonary and lung tumor microenvironments. EMT and EMT-associated phenotypes are related to cell invasion, PD-L1 upregulation, and chemoresistance (55). The inflammatory cytokine TNF- $\alpha$ can stabilize Snail through activation of the nuclear factor-kappa $\mathrm{B}(\mathrm{NF}-\kappa \mathrm{B})$ pathway, which plays a critical role in inflammation-induced EMT and cancer cell migration, invasion, and metastasis (56). COX-2 stimulates the RhoA/Rho kinase pathway, which leads to disruption of tumor cell adherens junction formation and contributes to tumor progression (57). COX-2 is also overexpressed in NSCLC tissue and correlates with an unfavorable prognosis (58). In summary, pathogenic microorganisms infection can promote the release of inflammatory cytokines and aggravate local inflammatory response, thus promoting the occurrence and development of tumors.

The positive rate of the H.pylori (HP) in gastric cancer patients was positively correlated with the expression of macrophage migration inhibition factor (MIF) (59). The expression of Mif can promote cell transformation, tumor cell proliferation, and metastasis. Moreover, the expression of Mif was shown to be upregulated in NSCLC (60). The isolation and characterization of individual circulating tumor cells (CTCs)-associated white blood cells (WBCs) (CTCs-WBCs) as well as corresponding cancer cells within each CTCs-WBCs cluster showed that neutrophils and CTCs interact within the blood, and this interaction promotes cell cycle progression, which enhances the possibility of tumor metastasis of CTCs (61). COPD is at high risk of lung cancer (48). Non-typeable Haemophilus influenzae (NTHi) colonization can increase the frequency of exacerbations of COPD (62). Compared with the air-exposed group, when $I L-17 C$ genedeficient metastatic lung cancer mice were exposed to NTHi, there was a significant reduction in the proliferation, growth, and number of tumor-associated neutrophils, suggesting that IL-17C plays a role in the development of neutrophil-mediated lung cancer (63).

Escherichia coli becomes highly pathogenic following the acquisition of virulence factors, including the protein toxin cytotoxic necrotizing factor 1 (CNF1), which induces the expression of $\mathrm{COX} 2$, activates the transcription factor NF- $\kappa \mathrm{B}$, and promotes cellular motility, and thereby promotes tumor development (64). CNF1-induced bladder cancer cells secrete vascular endothelial growth factor (VEGF), leading to subsequent angiogenesis in the cancer microenvironment (65). Cytolethal distending toxin exposure leads to a unique cytotoxicity and induces a cell cycle arrest dependent on the DNA damage response (66). Moreover, enterotoxigenic Bacteroides fragilis and B. fragilis toxin gene was upregulated in patients with precancerous and cancerous lesions (67). Besides, microbial fermentation may have negative consequences owing to the generation of potentially toxic and cancer-promoting metabolites, such as ammonia, amines, phenols, sulphides, and nitrosamines (68). The microbiota modulates the enterohepatic circulation of estrogens through their ability to deconjugate estrogens, thus affecting circulating and excreted estrogen levels, and the risk for development of estrogendependent cancers (69). Overall, the role of inflammation and immunity in lung cancer development has been established; however, the correlation and interaction between pulmonary microorganisms and lung cancer are still not clear.

\section{New Directions for Cancer Treatment}

There are new directions in cancer treatment with improved understanding of the correlation among microbes, inflammation, and cancer. For example, meroterpenoids, isolated from the brown seaweed Cystoseira usneoides, significantly reduced the production of TNF- $\alpha$, IL- 6 , and IL- $1 \beta$, suppressed COX- 2 expression, and displayed higher cytotoxic activities against lung cancer cells compared with normal lung cells (70). COX-2 can also enhance gefitinib resistance and NSCLC metastasis via PI3K-AKT silencing, which is a novel therapeutic strategy to overcome gefitinib resistance in NSCLC cells (58). On the other hand, a curative effect was observed following transplantation of the dominant intestinal flora of patients into the intestinal tract of a lung cancer mouse model (28). Smaller tumors and an improved survival rate were observed in lung cancer mice treated with cisplatin combined 
with Lactobacillus bacteria (29). Moreover, antibodies targeting cytotoxic T-lymphocyte antigen (CTLA)-4 have been successfully used as cancer immunotherapy; the anticancer activity of CTLA-4 depends on intestinal flora. Investigations have confirmed that Bifidobacterium enhances the therapeutic effects of PD-L1 and CTLA- 4 by altering the activity of dendritic cells and enhancing $\mathrm{CD}^{+} \mathrm{T}$ cell activation $(71,72)$. A recent investigation found that there are many intestinal fungi in the tumor tissues of pancreatic ductal adenocarcinoma (PDA) cells. Furthermore, the elimination of fungi can inhibit the growth of tumors in PDA mice and improve the effects of chemotherapy (73). The antitumor effects of the microbiome may be influenced by the type and strength of the immune response and cross-reactions between the microbiome and tumor antigen (74). However, further exploration of the use of microorganisms in the treatment of tumors is necessary.

\section{LUNG CANCER BIOMARKERS}

\section{Development of Lung Cancer Biomarkers}

There are many biomarkers for lung cancer. For example, the sensitivity of a panel of autoantibodies to tumor-associated antigens was higher than a single antigen. However, only $40 \%$ of primary lung cancers can be identified by testing with a panel of autoantibodies in peripheral blood (75). Comprehensive assessment of suspected lung cancer using circulating microRNAs (miRNAs) can effectively reduce the false positive rate of LDCT and can also be used to monitor cancer recurrence (76). The detection of mature mir-21 in the sputum of 23 lung cancer patients showed that the expression of mir-21 was significantly higher than that of noncancer patients, with a detection rate of $69.66 \%$ and specificity of $100.00 \%$ (77). Circulating tumor DNA is frequently present in patients with advanced NSCLC, which can be used to assess the clinical benefits of Nivolumab (78). However, it can only be used to assess recurrence after primary surgery for NSCLC (79). Elevated levels of IL-6, IL-8, and C-reactive protein are associated with the diagnosis of lung cancer. The levels of IL- 8 begin to increase 5 years prior to the diagnosis of lung cancer. Therefore, the combination of IL-6 and IL-8 could be useful for evaluating the prognosis of lung cancer (80). Detection of exhaled breath volatile organic compounds by special instruments may also be useful in the diagnosis and classification of cancer (81). Compared with cancer-free specimens, measurement of metabolites in sputum samples of lung cancer patients revealed that levels of isobutyl decanoate, putrescine, diethyl glutarate, and cysteamine were significantly changed (82), suggesting that metabolites in sputum may act as biomarkers for lung cancer. Although detection biomarkers for lung cancer are diverse, precision by these biomarkers has not yet been achieved. Further research should be performed in large and well designed trials as most data is retrospective or in small series.

\section{Microbiome and Potential Microbial Markers of Lung Cancer}

At present, several investigations have confirmed changes in lung microecology in lung cancer; however, different changes in the bacterial flora of lung cancer patients were observed in different specimens. BAL samples from lung cancer patients had elevated levels of Firmicutes and TM7 kingdom; levels of the genera Veillonella and Megasphaera were also increased significantly (7). PSB samples from lung cancer patients revealed that the levels of Streptococcus in lung cancer were significantly higher compared with the non-cancerous control. An upward trend of Neisseria in cancerous lesions and Staphylococcus and Dialister displayed a decreasing trend in the non-cancerous group compared with the cancer group. Significantly decreased microbial diversity in lung cancer has also been observed (8). Moreover, the abundance of Firmicutes (Streptococcus) and Bacteroides (Prevotella) was significantly increased in the lung tissues of patients with surgically treated lung cancer compared with emphysema patients (83). 16S rDNA sequencing analysis showed that the abundance of salivary species in patients with lung cancer differed from the non-cancerous group. Compared with the non-cancerous group at the genus level, the abundances of Capnocytophaga, Selenomonas, and Veillonella were higher and the abundance of Neisseria was lower in lung cancer patients. At the species level, compared with the squamous cell carcinoma group, the abundances of Streptococcus and Porphyromonas in adenocarcinoma patients were higher. Neisseria, Capnocytophaga, and Veillonella may be potential biomarkers of lung cancer (84). Another metagenomic sequence analysis found that the abundance of Granulicatella adiacens, Streptococcus intermedius, S. viridans, and M. tuberculosis in the sputum of patients with lung cancer was significantly higher compared with the non-cancerous group. The dominant trend of G. adiacens is related to Enterococcus sp.130, E. coli, S. intermedius, Acinetobacter junii, S. viridans, and S. sp.6. Significant changes in level 2 and 3 functions, such as urea cycle, putrescine utilization, and intracellular resistance, were also observed from negative to positive lung cancer. However, compared with the non-cancerous group, there was no significant change in sputum species diversity in lung cancer patients (85). Compared with the non-cancerous group, the analysis of $16 \mathrm{~S} \mathrm{rDNA}$ high-throughput sequencing of sputum from non-smoking female lung cancer patients found that the relative abundances of Granulicatella (6.1\%), Abiotrophia (1.5\%) and Streptococcus $(40.1 \%)$ were significantly increased (86). Compared with squamous cell carcinoma, the abundances of Thermus and Ralstonia were higher and lower, respectively, in adenocarcinoma. Alpha diversity is statistically significantly higher in patients with adenocarcinoma (87). In addition, TP53 mutations have been shown to be related to the abundance of microorganisms in squamous cell carcinoma (88). Further investigation found that a number of microorganisms, including Acidovorax, Klebsiella, Rhodoferax, Comamonas, and Polarmonas, were more abundant in squamous cell carcinoma with TP53 mutations (89).

Table 1 shows a summary of the relevant studies; overall, the pulmonary microbiome in lung cancer patients differs from that in tumor-free patients. In terms of biodiversity, the results are inconsistent, which may be related to small sample sizes and clinical sampling differences. Several studies have shown that the abundance of Streptococcus (Firmicutes) in lung cancer patient samples was significantly increased. In vitro, investigations have 
TABLE 1 | Microorganisms with varying abundance in lung cancer patients.

\begin{tabular}{|c|c|c|c|}
\hline $\begin{array}{l}\text { Sample } \\
\text { type }\end{array}$ & $\begin{array}{l}\text { Control } \\
\text { group }\end{array}$ & Main finding & Reference \\
\hline BAL & Tumor free & $\begin{array}{l}\text { Phylum: Firmicutes and TM7 increased in lung cancer group; } \\
\text { Genus: Veillonella, Megasphaera, Atopobium, and Selenomonas increased in lung cancer group; } \\
\text { Alpha diversity increased in lung cancer group; }\end{array}$ & Lee et al. (7) \\
\hline PBS & Healthy & $\begin{array}{l}\text { Genus: Streptococcus, Haemophilus, and Neisseria increased in lung cancer group; Staphylococcus and Dialister decreased } \\
\text { in lung cancer group; } \\
\text { Alpha diversity decreased in lung cancer group; }\end{array}$ & Liu et al. (8) \\
\hline $\begin{array}{l}\text { Lung } \\
\text { tissue }\end{array}$ & Emphysema & $\begin{array}{l}\text { Phylum: Firmicutes, Bacteroidetes, and Actinobacteria increased in lung cancer group; Proteobacteria decreased in lung } \\
\text { cancer group; } \\
\text { Genus: Streptococcus, Prevotella, and Bifidobacterium increased in lung cancer group; Acinetobacter, Acidovorax, and } \\
\text { Diaphorobacter decreased in lung cancer group; } \\
\text { Alpha diversity increased in lung cancer group; }\end{array}$ & Liu et al. (83) \\
\hline Salivary & Tumor free & $\begin{array}{l}\text { Order: Flavobacteriales and Burkholderiales increased in lung cancer group; Bacteroidales decreased in lung cancer group; } \\
\text { Family: Veillonellaceae increased in lung cancer group; Lachnospiraceae decreased in lung cancer group; } \\
\text { Genus: Capnocytophaga, Selenomonas, and Veillonella increased in lung cancer group; Neisseria and Streptococcus } \\
\text { decreased in lung cancer group; } \\
\text { The abundances of Streptococcus and Porphyromonas in adenocarcinoma patients was higher than in squamous cell } \\
\text { carcinoma patients; }\end{array}$ & Yan et al. (84) \\
\hline Sputum & Tumor free & $\begin{array}{l}\text { Species: Streptococcus viridans, Streptococcus intermedius, Granulicatella adiacens, Mycobacterium tuberculosis, and } \\
\text { Mycobacterium bovis increased in lung cancer group; } \\
\text { Alpha diversity was not significantly different in the lung cancer group; }\end{array}$ & $\begin{array}{l}\text { Cameron } \\
\text { et al. (85) }\end{array}$ \\
\hline Sputum & Tumor free & $\begin{array}{l}\text { Genus: Streptococcus, Abiotrophia, and Granulicatella increased in lung cancer group; Leptotrichia, Sphingomonas } \\
\text { decreased in lung cancer group; }\end{array}$ & $\begin{array}{l}\text { Hosgood } \\
\text { et al. (86) }\end{array}$ \\
\hline $\begin{array}{l}\text { Lung } \\
\text { tissue }\end{array}$ & - & $\begin{array}{l}\text { Adenocarcinoma vs. squamous cell carcinoma: abundance of Thermus was higher in adenocarcinoma, abundance of } \\
\text { Ralstonia was lower in adenocarcinoma; } \\
\text { Alpha diversity was statistically significantly higher in patients with adenocarcinoma; }\end{array}$ & Yu et al. (87) \\
\hline
\end{tabular}

BAL, bronchoalveolar lavage; PSB, protected specimen brushing; "-", null.

revealed that $S$. pneumoniae can cause damage to alveolar epithelial cells (90). Similar results have confirmed that $S$. pneumoniae directly inhibits purinergic signaling by inducing purinergic receptor $\mathrm{P} 2 \mathrm{Y} 2$ phosphorylation and internalization, which can lead to suppression of the calcium response of alveolar epithelial cells to ATP and affect the cellular integrity and function (91). Streptococcus may promote the development of lung cancer, although further experiments are needed for verification.

\section{CONCLUSIONS AND PROSPECTS}

Over the past few decades, significant progress has been made in our understanding of the relationship between the microbiome and lung cancer. From the above-mentioned investigations, we know that the microbiota of lung cancer patients is changed, and the abundance of certain bacteria in lung cancer patients is significantly increased. However, how the changes in the composition and metabolism of the microbiome contribute to lung cancer development remains largely unexplored. As the small sample sizes, the investigations of the microbiome in lung cancer remain at analysis of the rule of microbiome change. Further investigations are needed to clarify the mechanism underlying the influence of the microbiome on the occurrence and development of lung cancer and interactions between the microbiome and lung cancer. If the increased abundance of microorganisms in lung cancer patients promotes the progression of lung cancer, then early monitoring and intervention for the screening and treatment of lung cancer patients become particularly important. Further understanding of these mechanisms will shed light on early screening, diagnosis, and treatment of lung cancer.

\section{AUTHOR CONTRIBUTIONS}

ZNR, CYX, and ZYS wrote the manuscript. JXL and FW critically revised it. ZYS and BX supervised the work. All authors contributed to the article and approved the submitted version.

\section{FUNDING}

This research was funded by the National Natural Science Foundation of the China (31701127), Science and Technology Project of Sichuan (2019YJ0407, 2017JY0165), and Foundation of Affiliated Hospital of Southwest Medical University (2015-YJ011).

\section{ACKNOWLEDGMENTS}

We would like to apologize for any omission in referencing owing to space restrictions. 


\section{REFERENCES}

1. Li W, Deng Y, Chu Q, Zhang P. Gut microbiome and cancer immunotherapy. Cancer Lett (2019) 447:41-7. doi: 10.1016/j.canlet.2019.01.015

2. McFarland LV, Ozen M, Dinleyici EC, Goh S. Comparison of pediatric and adult antibiotic-associated diarrhea and Clostridium difficile infections. World J Gastroenterol (2016) 22:3078-104. doi: 10.3748/wjg.v22.i11.3078

3. Kim SH, Clark ST, Surendra A, Copeland JK, Wang PW, Ammar R, et al. Global Analysis of the Fungal Microbiome in Cystic Fibrosis Patients Reveals Loss of Function of the Transcriptional Repressor Nrg1 as a Mechanism of Pathogen Adaptation. PLoS Pathog (2015) 11:e1005308. doi: 10.1371/ journal.ppat.1005308

4. Helicobacter, Cancer Collaborative G. Gastric cancer and Helicobacter pylori: a combined analysis of 12 case control studies nested within prospective cohorts. Gut (2001) 49:347-53. doi: 10.1136/gut.49.3.347

5. Murphy TF, Brauer AL, Schiffmacher AT, Sethi S. Persistent colonization by Haemophilus influenzae in chronic obstructive pulmonary disease. Am J Respir Crit Care Med (2004) 170:266-72. doi: 10.1164/rccm.200403-354OC

6. Froidure A, Pilette C. From the hygiene hypothesis to A20: the protective effect of endotoxins against asthma development. Clin Exp Allergy (2016) 46:192-3. doi: 10.1111/cea.12651

7. Lee SH, Sung JY, Yong D, Chun J, Kim SY, Song JH, et al. Characterization of microbiome in bronchoalveolar lavage fluid of patients with lung cancer comparing with benign mass like lesions. Lung Cancer (2016) 102:89-95. doi: 10.1016/j.lungcan.2016.10.016

8. Liu HX, Tao LL, Zhang J, Zhu YG, Zheng Y, Liu D, et al. Difference of lower airway microbiome in bilateral protected specimen brush between lung cancer patients with unilateral lobar masses and control subjects. Int $J$ Cancer (2018) 142:769-78. doi: 10.1002/ijc.31098

9. Curiel TJ, Coukos G, Zou L, Alvarez X, Cheng P, Mottram P, et al. Specific recruitment of regulatory $\mathrm{T}$ cells in ovarian carcinoma fosters immune privilege and predicts reduced survival. Nat Med (2004) 10:942-9. doi: 10.1038/nm1093

10. Trop-Steinberg S, Azar Y. Is Myc an Important Biomarker? Myc Expression in Immune Disorders and Cancer. Am J Med Sci (2018) 355:67-75. doi: 10.1016/ j.amjms.2017.06.007

11. Tsukamoto T, Mizoshita T, Tatematsu M. Animal models of stomach carcinogenesis. Toxicol Pathol (2007) 35:636-48. doi: 10.1080/0192623070 1420632

12. Balkwill F, Mantovani A. Inflammation and cancer: back to Virchow? Lancet (2001) 357:539-45. doi: 10.1016/S0140-6736(00)04046-0

13. Mantovani A, Allavena P, Sica A, Balkwill F. Cancer-related inflammation. Nature (2008) 454:436-44. doi: 10.1038/nature07205

14. Brenner DR, McLaughlin JR, Hung RJ. Previous lung diseases and lung cancer risk: a systematic review and meta-analysis. PLoS One (2011) 6:e17479. doi: 10.1371/journal.pone.0017479

15. Punturieri A, Szabo E, Croxton TL, Shapiro SD, Dubinett SM. Lung cancer and chronic obstructive pulmonary disease: needs and opportunities for integrated research. J Natl Cancer Inst (2009) 101:554-9. doi: 10.1093/jnci/ djp023

16. Torre LA, Siegel RL, Jemal A. Lung Cancer Statistics. Adv Exp Med Biol (2016) 893:1-19. doi: 10.1007/978-3-319-24223-1_1

17. Bray F, Ferlay J, Soerjomataram I, Siegel RL, Torre LA, Jemal A. Global cancer statistics 2018: GLOBOCAN estimates of incidence and mortality worldwide for 36 cancers in 185 countries. CA Cancer J Clin (2018) 68:394-424. doi: $10.3322 /$ caac. 21492

18. Miller KD, Siegel RL, Lin CC, Mariotto AB, Kramer JL, Rowland JH, et al. Cancer treatment and survivorship statistics, 2016. CA Cancer J Clin (2016) 66:271-89. doi: 10.3322/caac.21349

19. Seiler CL, Song JM, Fernandez J, Abrahante JE, Kono TJY, Chen Y, et al. Epigenetic Changes in Alveolar Type II Lung Cells of A/J Mice Following Intranasal Treatment with Lipopolysaccharide. Chem Res Toxicol (2019) 32:831-9. doi: 10.1021/acs.chemrestox.9b00015

20. Mao Q, Jiang F, Yin R, Wang J, Xia W, Dong G, et al. Interplay between the lung microbiome and lung cancer. Cancer Lett (2018) 415:40-8. doi: 10.1016/ j.canlet.2017.11.036

21. Engels EA. Inflammation in the development of lung cancer: epidemiological evidence. Expert Rev Anticancer Ther (2008) 8:605-15. doi: 10.1586/147371 40.8.4.605
22. Gettinger S, Horn L, Jackman D, Spigel D, Antonia S, Hellmann M, et al. FiveYear Follow-Up of Nivolumab in Previously Treated Advanced Non-SmallCell Lung Cancer: Results From the CA209-003 Study. J Clin Oncol (2018) 36:1675-84. doi: 10.1200/JCO.2017.77.0412

23. Herbst RS, Baas P, Kim DW, Felip E, Perez-Gracia JL, Han JY, et al. Pembrolizumab versus docetaxel for previously treated, PD-L1-positive, advanced non-small-cell lung cancer (KEYNOTE-010): a randomised controlled trial. Lancet (2016) 387:1540-50. doi: 10.1016/S0140-6736(15) 01281-7

24. Routy B, Le Chatelier E, Derosa L, Duong CPM, Alou MT, Daillere R, et al. Gut microbiome influences efficacy of PD-1-based immunotherapy against epithelial tumors. Science (2018) 359:91-7. doi: 10.1126/science.aan3706

25. Gopalakrishnan V, Spencer CN, Nezi L, Reuben A, Andrews MC, Karpinets TV, et al. Gut microbiome modulates response to anti-PD-1 immunotherapy in melanoma patients. Science (2018) 359:97-103. doi: 10.1126/science.aan 4236

26. Matson V, Fessler J, Bao R, Chongsuwat T, Zha Y, Alegre ML, et al. The commensal microbiome is associated with anti-PD-1 efficacy in metastatic melanoma patients. Science (2018) 359:104-8. doi: 10.1126/science.aao3290

27. Vetizou M, Trinchieri G. Anti-PD1 in the wonder-gut-land. Cell Res (2018) 28:263-4. doi: 10.1038/cr.2018.12

28. Heshiki Y, Vazquez-Uribe R, Li J, Ni Y, Quainoo S, Imamovic L, et al. Predictable modulation of cancer treatment outcomes by the gut microbiota. Microbiome (2020) 8:28-41. doi: 10.1186/s40168-020-00811-2

29. Gui QF, Lu HF, Zhang CX, Xu ZR, Yang YH. Well-balanced commensal microbiota contributes to anti-cancer response in a lung cancer mouse model. Genet Mol Res (2015) 14:5642-51. doi: 10.4238/2015.May.25.16

30. Budden KF, Shukla SD, Rehman SF, Bowerman KL, Keely S, Hugenholtz P, et al. Functional effects of the microbiota in chronic respiratory disease. Lancet Respir Med (2019) 7:907-20. doi: 10.1016/S2213-2600(18)30510-1

31. Dickson RP, Erb-Downward JR, Freeman CM, McCloskey L, Falkowski NR, Huffnagle GB, et al. Bacterial Topography of the Healthy Human Lower Respiratory Tract. MBio (2017) 8:e02287-16. doi: 10.1128/mBio.02287-16

32. Surette MG. The cystic fibrosis lung microbiome. Ann Am Thorac Soc (2014) 11 Suppl 1:S61-5. doi: 10.1513/AnnalsATS.201306-159MG

33. Segal LN, Alekseyenko AV, Clemente JC, Kulkarni R, Wu B, Gao Z, et al. Enrichment of lung microbiome with supraglottic taxa is associated with increased pulmonary inflammation. Microbiome (2013) 1:19. doi: 10.1186/ 2049-2618-1-19

34. Moffatt MF, Cookson WO. The lung microbiome in health and disease. Clin Med (Lond) (2017) 17:525-29. doi: 10.7861/clinmedicine.17-6-525

35. Li KJ, Chen ZL, Huang Y, Zhang R, Luan XQ, Lei TT, et al. Dysbiosis of lower respiratory tract microbiome are associated with inflammation and microbial function variety. Respir Res (2019) 20:272. doi: 10.1186/s12931-019-1246-0

36. Smith DJ, Badrick AC, Zakrzewski M, Krause L, Bell SC, Anderson GJ, et al. Pyrosequencing reveals transient cystic fibrosis lung microbiome changes with intravenous antibiotics. Eur Respir J (2014) 44:922-30. doi: 10.1183/ 09031936.00203013

37. Dickson RP, Martinez FJ, Huffnagle GB. The role of the microbiome in exacerbations of chronic lung diseases. Lancet (2014) 384:691-702. doi: 10.1016/S0140-6736(14)61136-3

38. Feigelman R, Kahlert CR, Baty F, Rassouli F, Kleiner RL, Kohler P, et al. Sputum DNA sequencing in cystic fibrosis: non-invasive access to the lung microbiome and to pathogen details. Microbiome (2017) 5:20. doi: 10.1186/ s40168-017-0234-1

39. Huber JA, Mark Welch DB, Morrison HG, Huse SM, Neal PR, Butterfield DA, et al. Microbial population structures in the deep marine biosphere. Science (2007) 318:97-100. doi: 10.1126/science.1146689

40. Blainey PC, Milla CE, Cornfield DN, Quake SR. Quantitative analysis of the human airway microbial ecology reveals a pervasive signature for cystic fibrosis. Sci Transl Med (2012) 4:153ra30. doi: 10.1126/scitranslmed.3004458

41. Charlson ES, Bittinger K, Haas AR, Fitzgerald AS, Frank I, Yadav A, et al. Topographical continuity of bacterial populations in the healthy human respiratory tract. Am J Respir Crit Care Med (2011) 184:957-63. doi: 10.1164/rccm.201104-0655OC

42. Cui L, Lucht L, Tipton L, Rogers MB, Fitch A, Kessinger C, et al. Topographic diversity of the respiratory tract mycobiome and alteration in HIV and lung disease. Am J Respir Crit Care Med (2015) 191:932-42. doi: 10.1164/ rccm.201409-1583OC 
43. Hobby GP, Karaduta O, Dusio GF, Singh M, Zybailov BL, Arthur JM. Chronic kidney disease and the gut microbiome. Am J Physiol Renal Physiol (2019) 316:F1211-F7. doi: 10.1152/ajprenal.00298.2018

44. Dong TS, Jacobs JP. Nonalcoholic fatty liver disease and the gut microbiome: Are bacteria responsible for fatty liver? Exp Biol Med (Maywood) (2019) 244:408-18. doi: 10.1177/1535370219836739

45. Trompette A, Gollwitzer ES, Yadava K, Sichelstiel AK, Sprenger N, Ngom-Bru $\mathrm{C}$, et al. Gut microbiota metabolism of dietary fiber influences allergic airway disease and hematopoiesis. Nat Med (2014) 20:159-66. doi: 10.1038/nm.3444

46. Dang AT, Marsland BJ. Microbes, metabolites, and the gut-lung axis. Mucosal Immunol (2019) 12:843-50. doi: 10.1038/s41385-019-0160-6

47. Young RP, Hopkins RJ, Christmas T, Black PN, Metcalf P, Gamble GD. COPD prevalence is increased in lung cancer, independent of age, sex and smoking history. Eur Respir J (2009) 34:380-6. doi: 10.1183/09031936. 00144208

48. Park HY, Kang D, Shin SH, Yoo KH, Rhee CK, Suh GY, et al. Chronic obstructive pulmonary disease and lung cancer incidence in never smokers: a cohort study. Thorax (2020) 75:506-9. doi: 10.1136/thoraxjnl-2019-213732

49. Vestbo J. COPD: definition and phenotypes. Clin Chest Med (2014) 35:1-6. doi: $10.1016 /$ j.ccm.2013.10.010

50. Matkovic Z, Miravitlles M. Chronic bronchial infection in COPD. Is There An Infective Phenotype? Respir Med (2013) 107:10-22. doi: 10.1016/j.rmed. 2012.10.024

51. Leung JM, Tiew PY, Mac Aogain M, Budden KF, Yong VF, Thomas SS, et al. The role of acute and chronic respiratory colonization and infections in the pathogenesis of COPD. Respirology (2017) 22:634-50. doi: 10.1111/resp.13032

52. Parris BA, O'Farrell HE, Fong KM, Yang IA. Chronic obstructive pulmonary disease (COPD) and lung cancer: common pathways for pathogenesis. J Thorac Dis (2019) 11:S2155-S72. doi: 10.21037/jtd.2019.10.54

53. Deng B, Li Y, Zhang Y, Bai L, Yang P. Helicobacter pylori infection and lung cancer: a review of an emerging hypothesis. Carcinogenesis (2013) 34:1189-95. doi: $10.1093 /$ carcin/bgt114

54. Gocheva V, Wang HW, Gadea BB, Shree T, Hunter KE, Garfall AL, et al. IL-4 induces cathepsin protease activity in tumor-associated macrophages to promote cancer growth and invasion. Genes Dev (2010) 24:241-55. doi: $10.1101 /$ gad. 1874010

55. Li R, Ong SL, Tran LM, Jing Z, Dubinett S. Chronic il-1ß-induced inflammation regulates epithelial-to-mesenchymal transition memory phenotypes via epigenetic modifications in non-small cell lung cancer. Sci Rep (2020) 10:377-91. doi: 10.1038/s41598-019-57285-y

56. Wu Y, Deng J, Rychahou PG, Qiu S, Evers BM, Zhou BP. Stabilization of snail by NF-kappaB is required for inflammation-induced cell migration and invasion. Cancer Cell (2009) 15:416-28. doi: 10.1016/j.ccr.2009.03.016

57. Chang YWE, Marlin JW, Chance TW, Jakobi R. Rhoa mediates cyclooxygenase-2 signaling to disrupt the formation of adherens junctions and increase cell motility. Cancer Res (2006) 66:11700-8. doi: 10.1158/00085472.CAN-06-1818

58. Deng QF, Fang QY, Ji XX, Zhou SW. Cyclooxygenase-2 mediates gefitinib resistance in non-small cell lung cancer through the EGFR/PI3K/AKT axis. J Cancer (2020) 11:3667-74. doi: 10.7150/jca.42850

59. Yoon K, Kim N, Park Y, Kim BK, Park JH, Shin CM, et al. Correlation between macrophage migration inhibitory factor and autophagy in Helicobacter pylori-associated gastric carcinogenesis. PLoS One (2019) 14: e0211736. doi: 10.1371/journal.pone.0211736

60. Wang WM, Liu JC. Effect and molecular mechanism of mir-146a on proliferation of lung cancer cells by targeting and regulating MIF gene. Asian Pac J Trop Med (2016) 9:806-11. doi: 10.1016/j.apjtm.2016.06.001

61. Szczerba BM, Castro-Giner F, Vetter M, Krol I, Gkountela S, Landin J, et al. Neutrophils escort circulating tumour cells to enable cell cycle progression. Nature (2019) 566:553-7. doi: 10.1038/s41586-019-0915-y

62. Sethi S. Infection as a comorbidity of COPD. Eur Respir J (2010) 35:1209-15. doi: 10.1183/09031936.00081409

63. Jungnickel C, Schmidt LH, Bittigkoffer L, Wolf L, Wolf A, Ritzmann F, et al. IL-17C mediates the recruitment of tumor-associated neutrophils and lung tumor growth. Oncogene (2017) 36:4182-90. doi: 10.1038/onc.2017.28

64. Travaglione S, Fabbri A, Fiorentini C. The Rho-activating CNF1 toxin from pathogenice E. coli: a risk factor for human cancer development? Infect Agents Cancer (2008) 3:4-12. doi: 10.1186/1750-9378-3-4
65. Yaxiu G, Jingyu W, Kaichen Z, Junqiang L, Lei W, Shan G, et al. Cytotoxic necrotizing factor 1 promotes bladder cancer angiogenesis through activating RhoC. FASEB J (2020) 00:1-14. doi: 10.1096/fj.201903266RR

66. Elisabeth B, Julien V, Gladys M. The cytolethal distending toxin effects on Mammalian cells: a DNA damage perspective. Cells (2014) 3:592-615. doi: 10.3390/cells3020592

67. Zamani S, Taslimi R, Sarabi A, Jasemi S, Sechi LA, Feizabadi MM. Enterotoxigenic Bacteroides fragilis: A Possible Etiological Candidate for Bacterially-Induced Colorectal Precancerous and Cancerous Lesions. Front Cell Infect Microbiol (2019) 9:449-55. doi: 10.3389/fcimb.2019.00449

68. Schwabe RF, Jobin C. The microbiome and cancer. Nat Rev Cancer (2013) 13:800-12. doi: 10.1038/nrc3610

69. Plottel CS, Blaser MJ. Microbiome and malignancy. Cell Host Microbe (2011) 10:324-35. doi: 10.1016/j.chom.2011.10.003

70. Zbakh H, Zubia E, de Los Reyes C, Calderon-Montano JM, Lopez-Lazaro M, Motilva V. Meroterpenoids from the Brown Alga Cystoseira usneoides as Potential Anti-Inflammatory and Lung Anticancer Agents. Mar Drugs (2020) 18:207-22. doi: 10.3390/md18040207

71. Vetizou M, Pitt JM, Daillere R, Lepage P, Waldschmitt N, Flament C, et al. Anticancer immunotherapy by CTLA-4 blockade relies on the gut microbiota. Science (2015) 350:1079-84. doi: 10.1126/science.aad 1329

72. Sivan A, Corrales L, Hubert N, Williams JB, Aquino-Michaels K, Earley ZM, et al. Commensal Bifidobacterium promotes antitumor immunity and facilitates anti-PD-L1 efficacy. Science (2015) 350:1084-9. doi: 10.1126/ science.aac 4255

73. Aykut B, Pushalkar S, Chen R, Li Q, Abengozar R, Kim JI, et al. The fungal mycobiome promotes pancreatic oncogenesis via activation of MBL. Nature (2019) 574:264-7. doi: 10.1038/s41586-019-1608-2

74. Zitvogel L, Ayyoub M, Routy B, Kroemer G. Microbiome and Anticancer Immunosurveillance. Cell (2016) 165:276-87. doi: 10.1016/j.cell.2016.03.001

75. Boyle P, Chapman CJ, Holdenrieder S, Murray A, Robertson C, Wood WC, et al. Clinical validation of an autoantibody test for lung cancer. Ann Oncol (2011) 22:383-9. doi: 10.1093/annonc/mdq361

76. Sestini S, Boeri M, Marchiano A, Pelosi G, Galeone C, Verri C, et al. Circulating microRNA signature as liquid-biopsy to monitor lung cancer in low-dose computed tomography screening. Oncotarget (2015) 6:32868-77. doi: $10.18632 /$ oncotarget.5210

77. Xie Y, Todd NW, Liu Z, Zhan M, Fang H, Peng H, et al. Altered miRNA expression in sputum for diagnosis of non-small cell lung cancer. Lung Cancer (2010) 67:170-6. doi: 10.1016/j.lungcan.2009.04.004

78. Etienne GL, Guillaume H, Coraline D, Catherine J, Thierry C. Circulating tumor DNA evaluated by next-generation sequencing is predictive of tumor response and prolonged clinical benefit with nivolumab in advanced nonsmall cell lung cancer. Oncoimmunology (2018) 7:e1424675. doi: 10.1080/ 2162402X.2018.1424675

79. Abbosh C, Birkbak NJ, Wilson GA, Jamal-Hanjani M, Constantin T, Salari R, et al. Phylogenetic ctDNA analysis depicts early-stage lung cancer evolution. Nature (2017) 545:446-51. doi: 10.1038/nature22364

80. Robles AI, Harris CC. Integration of multiple "OMIC" biomarkers: A precision medicine strategy for lung cancer. Lung Cancer (2017) 107:50-8. doi: 10.1016/j.lungcan.2016.06.003

81. Peng G, Hakim M, Broza YY, Billan S, Abdah-Bortnyak R, Kuten A, et al. Detection of lung, breast, colorectal, and prostate cancers from exhaled breath using a single array of nanosensors. Br J Cancer (2010) 103:542-51. doi: 10.1038/sj.bjc. 6605810

82. Cameron SJ, Lewis KE, Beckmann M, Allison GG, Ghosal R, Lewis PD, et al. The metabolomic detection of lung cancer biomarkers in sputum. Lung Cancer (2016) 94:88-95. doi: 10.1016/j.lungcan.2016.02.006

83. Liu Y, O’Brien JL, Ajami NJ, Scheurer ME, Amirian ES, Armstrong G, et al. Lung tissue microbial profile in lung cancer is distinct from emphysema. Am J Cancer Res (2018) 8:1775-87.

84. Yan X, Yang M, Liu J, Gao R, Hu J, Li J, et al. Discovery and validation of potential bacterial biomarkers for lung cancer. Am J Cancer Res (2015) 5:3111-22.

85. Cameron SJS, Lewis KE, Huws SA, Hegarty MJ, Lewis PD, Pachebat JA, et al. A pilot study using metagenomic sequencing of the sputum microbiome suggests potential bacterial biomarkers for lung cancer. PLoS One (2017) 12: e0177062. doi: 10.1371/journal.pone.0177062 
86. Hosgood HD,3, Sapkota AR, Rothman N, Rohan T, Hu W, Xu J, et al. The potential role of lung microbiota in lung cancer attributed to household coal burning exposures. Environ Mol Mutagen (2014) 55:643-51. doi: 10.1002/ em. 21878

87. Yu G, Gail MH, Consonni D, Carugno M, Humphrys M, Pesatori AC, et al. Characterizing human lung tissue microbiota and its relationship to epidemiological and clinical features. Genome Biol (2016) 17:163. doi: 10.1186/s13059-016-1021-1

88. Cancer Genome Atlas Research N. Comprehensive genomic characterization of squamous cell lung cancers. Nature (2012) 489:519-25. doi: 10.1038/ nature 11404

89. Leigh GK, White JR, Vargas AJ, Bliskovsky VV, Beck JA, Natalia VM, et al. Interaction between the microbiome and tp53 in human lung cancer. Genome Biol (2018) 19:123-38. doi: 10.1186/s13059-018-1501-6

90. Kooter IM, Alblas MJ, Jedynska AD, Steenhof M, Houtzager MM, Van Ras M. Alveolar epithelial cells (A549) exposed at the air-liquid interface to diesel exhaust: First study in TNO's powertrain test center. Toxicol In Vitro (2013) 27:2342-9. doi: 10.1016/j.tiv.2013.10.007
91. Olotu C, Lehmensiek F, Koch B, Kiefmann M, Riegel AK, Hammerschmidt S, et al. Streptococcus pneumoniae inhibits purinergic signaling and promotes purinergic receptor P2Y2 internalization in alveolar epithelial cells. J Biol Chem (2019) 294:12795-806. doi: 10.1074/jbc.RA118.007236

Conflict of Interest: The authors declare that the research was conducted in the absence of any commercial or financial relationships that could be construed as a potential conflict of interest.

The reviewer [QY] declared a shared affiliation with the authors, to the handling editor at the time of review.

Copyright (C) 2021 Ran, Liu, Wang, Xin, Xiong and Song. This is an open-access article distributed under the terms of the Creative Commons Attribution License (CC BY). The use, distribution or reproduction in other forums is permitted, provided the original author(s) and the copyright owner(s) are credited and that the original publication in this journal is cited, in accordance with accepted academic practice. No use, distribution or reproduction is permitted which does not comply with these terms. 